\title{
DEFICIT FOLLIES
}

Johannes Brumm

Xiangyu Feng

Laurence J. Kotlikoff

Felix Kubler

Working Paper 28952

http://www.nber.org/papers/w28952

\author{
NATIONAL BUREAU OF ECONOMIC RESEARCH \\ 1050 Massachusetts Avenue \\ Cambridge, MA 02138 \\ June 2021
}

We thank Oliver Blanchard and seminar participants at the International Monetary Fund (FAD) for very helpful comments. The views expressed herein are those of the authors and do not necessarily reflect the views of the National Bureau of Economic Research.

NBER working papers are circulated for discussion and comment purposes. They have not been peer-reviewed or been subject to the review by the NBER Board of Directors that accompanies official NBER publications.

(C) 2021 by Johannes Brumm, Xiangyu Feng, Laurence J. Kotlikoff, and Felix Kubler. All rights reserved. Short sections of text, not to exceed two paragraphs, may be quoted without explicit permission provided that full credit, including $(\odot$ notice, is given to the source. 
Deficit Follies

Johannes Brumm, Xiangyu Feng, Laurence J. Kotlikoff, and Felix Kubler

NBER Working Paper No. 28952

June 2021

JEL No. E21,E6,H6

\begin{abstract}
Deficit finance is free when the growth rate routinely exceeds the government's borrowing rate. Or so many people say. This note presents three counterexamples. Each features a simple OLG economy with a zero growth rate and a negative government borrowing rate. None provides a basis for taking from the young and giving to the old. One example features idiosyncratic risk, one features policy uncertainty, and one features a safe borrowing rate that exceeds the safe lending rate. Progressive taxation cures the first problem. Policy resolution cures the second. And improved intermediation, perhaps organized by the government, cures the third. The three models are parables. Each conveys an inconvenient truth. Seemingly free deficits may, on careful inspection, be far more costly than they appear. Indeed, government intergenerational redistribution can lower the government borrowing rate, encouraging yet more inefficient deficit finance.
\end{abstract}

Johannes Brumm

Karlsruhe Institute of Technology

Waldhornstr. 27

76131 Karlsruhe

Germany

jo.brumm@gmail.com

Xiangyu Feng

Boston University

270 Bay State Road

Boston, MA 02215

xyfeng@xmu.edu.cn
Laurence J. Kotlikoff

Department of Economics

Boston University

270 Bay State Road

Boston, MA 02215

and NBER

kotlikoff@gmail.com

Felix Kubler

University of Zurich

Plattenstrasse 32

CH-8032 Zurich

Switzerland

and Swiss Financial Institute

fkubler@gmail.com 


\section{Introduction}

Blanchard et al. (2020), Summers and Rachel (2019), Blanchard and Summers (2019), and Blanchard (2019), among others, suggest fiscal deficits may have no cost when public borrowing rates average less than economic growth rates. This note demurs. It presents three simple, twoperiod, zero-growth, OLG models, each of which features negative safe rates. None provides support for deficit finance, the essence of which is taking from the young to give to the old, henceforth, take-go policy. In the first model, the negative safe rate reflects idiosyncratic risk. In the second, it embeds both TFP risk and policy uncertainty. In the third, TFP risk plus imperfect intermediation drives the safe lending rate (i.e., the government borrowing rate) below the growth rate, while leaving the safe private borrowing rate above the growth rate. Model 1's risk is readily dispelled via progressive taxation. Model 2's risk, which can be extreme, can be reduced by constitutional or other policy-commitment mechanisms. Model 3's dispersion in safe rates can be ameliorated via improved intermediation, potentially with the help of government loan verification, collection, and enforcement.

The message of our missives is clear. Judging the welfare impact of take-go/deficit finance when interest rates are low is not as simple as it seems. Such policies may benefit current generations at the expense of future generations. They may produce policy risk, which, paradoxically, lowers the government's borrowing rate, encouraging yet more welfare-reducing deficit finance. And they may redistribute from borrowers to lenders, where the former face safe rates above and the later safe rates below the growth rate. Our three parables all show that a low government borrowing rate, in and of itself, does not justify deficit finance. Of course, there may be other reasons for such policies, not considered in our models, that merit consideration. Our contribution is simply to warn against taking low interest rates as sufficient ground for running deficits.

This paper complements Brumm et al. (2021), which traces Blanchard (2019)'s case for deficit finance not to intergenerational redistribution, but to intergenerational and international risk sharing as well as implicit beggar-thy-neighbor policy. For brevity, we refer readers to that paper for a discussion of these points and a review of the literature, particularly the many recent papers focused on take-go policy in low interest-rate environments.

\section{Idiosyncratic Risk}

Model 1's economy is deterministic. Production is linear in labor and capital with respective marginal products of 1 and $R$. Agents work when young and consume when old. They invest their wages in safe bonds and risky (to them) capital - capital that fully depreciates each period. Let $S$ denote the safe rate. Agents invest solely in their own firms and have an equal chance of earning $R H$ and $R L$, where

$$
H=1+\theta,
$$

and

$$
L=1-\theta .
$$

Thus, $H+L=2$. Agents comprise a continuum of measure 1 and their returns are independent. Hence, there is no aggregate risk. Expected utility of those born at $t$ is 


$$
E U_{t}=\frac{.5 C_{t+1, H}^{1-\gamma}}{1-\gamma}+\frac{.5 C_{t+1, L}^{1-\gamma}}{1-\gamma}
$$

where,

$$
\begin{aligned}
& C_{t+1, H}=\alpha S+(1-\alpha) R H, \\
& C_{t+1, L}=\alpha S+(1-\alpha) R L,
\end{aligned}
$$

and $\alpha$ is the share of saving invested in the safe bond. The net supply of these bonds is zero. When $S<1$, each unit of output saved and invested safely when young returns less than a unit when old. In contrast, each unit contributed when young to take-go is reciprocated with a full unit of consumption when old. The optimal choice of $\alpha$ plus the equilibrium condition, $\alpha=0$, imply

$$
S=R \frac{H L^{\gamma}+L H^{\gamma}}{H^{\gamma}+L^{\gamma}}
$$

When there is no risk, there is no risk premium, i.e., when $H=L=1, S=R$. The same is true if agents are risk neutral $(\gamma=0)$. When $\gamma=1$, the logarithmic case, $S=R H L$. If $\theta=0.5$, $H L$ equals 0.75 and $R$ exceeds $S$ by one third. Thus, a value of $R$ below 1.33 implies $S<1$, which means a higher return to take-go policy than investing safely. As $\gamma$ rises, $S$ converges to $\mathrm{RL}$ and the percentage risk premium converges to $(R-R L) / R L$, which, in this example, equals 100 percent.

\section{Progressive Taxation Versus Take-Go Policy}

The government can eliminate idiosyncratic-return risk by transferring $\theta R$ from those earning high returns to those earning low returns. Doing so raises $S$ to $R$. It also raises the expected utility of all current and future generations - those born at $t \geq-1$ from

$$
E U_{t}=\left(.5 H^{1-\gamma}+.5 L^{1-\gamma}\right) \frac{R^{1-\gamma}}{1-\gamma}
$$

to

$$
E U_{t}=\frac{R^{1-\gamma}}{1-\gamma}
$$

But what if such risk-sharing policy isn't undertaken? Instead, suppose that deficit proponents, observing that $S<1$, convince policymakers that deficits are free provided $S<1$ and that they should enact take-go, taking $T$ from the young each period and giving it to the old. $C_{t+1, H}$, $C_{t+1, L}$, and $S$ now satisfy

$$
\begin{aligned}
& C_{t+1, H}=\alpha(1-T) S+(1-\alpha)(1-T) R H+T, \\
& C_{t+1, L}=\alpha(1-T) S+(1-\alpha)(1-T) R L+T,
\end{aligned}
$$

and

$$
S=\frac{R H[(1-T) R L+T]^{\gamma}+R L[(1-T) R H+T]^{\gamma}}{[(1-T) R H+T]^{\gamma}+[(1-T) R L+T]^{\gamma}}
$$


where $S$ increases in $T$, equalling $R$ when $T=1$ and 1 for $T=T^{*}<1$. The impact on $E U_{t}$ for $t \geq 0$ per unit of expected marginal utility of consumption when old, $E U_{t}^{\prime}$, of an increase in $T$ is

$$
\frac{\partial E U_{t}}{\partial T}=(1-S) E U_{t}^{\prime}>0
$$

where

$$
E U_{t}^{\prime}=.5 C_{t+1, H}^{-\gamma}+.5 C_{t+1, L}^{-\gamma}
$$

which is always positive. For the initial old (born at $t-1$ ), the marginal impact of take-go is

$$
\frac{\partial E U_{t-1}}{\partial T}=E U_{t-1}^{\prime}
$$

Hence, introducing take-go can raise all generations' utilities relative to the no-policy equilibrium provided $S<1$. This is Blanchard (2019)'s ideal take-go setting. As long as $T \leq 1$, the policy is sustainable and, thanks to our assumed linear technology, there are no changes in factor prices arising from take-go's crowding out of capital. Such changes would otherwise lower wages of future generations, potentially precluding a Pareto improvement.

Presumably policymakers would set $T$ at the value $T^{*}$ at which $S=1$. When $\gamma=1, R=1.2$, $\theta=.5$, and $\gamma=1, T^{*}=.375$. In this case, expected utility of the initial old rises from (7) to (15). For initial young and future generations, utility rises from (7) to (16).

$$
\begin{gathered}
E U_{-1}=\frac{.5\left(R H+T^{*}\right)^{1-\gamma}}{1-\gamma}+\frac{.5\left(R L+T^{*}\right)^{1-\gamma}}{1-\gamma} . \\
E U_{-1}=\frac{.5\left(\left(1-T^{*}\right) R H+T^{*}\right)^{1-\gamma}}{1-\gamma}+\frac{.5\left(\left(1-T^{*}\right) R L+T^{*}\right)^{1-\gamma}}{1-\gamma} .
\end{gathered}
$$

Thus, relative to no-policy, all generations gain from setting $T$ to $T^{*}$. But take-go is not the only available Pareto improvement. One indicator of this is that take-go permanently reduces the economy's output. To see why, note that the no-policy economy's output is $1+R$ per period. Take-go policy with $T=T^{*}$ leaves output unchanged at $t=0$. Thereafter, output falls to $1+\left(1-T^{*}\right) R$ since setting $T$ to $T^{*}$ crowds out investment in productive, $R>1$, capital. In contrast, progressive taxation (risk-sharing policy) keeps output at $1+R$ forever. Instead of reducing the economy's productive capacity, it targets the real problem - inefficient risk allocation. Once implemented, everyone, including the initial old, consumes $1+R$ for sure when old. Compared with no policy, this raises all generations expected utility, including that of the initial old, from (7) to (8).

Admittedly, risk sharing is not as favorable to the initial old as take-go - i.e., (15) will generally exceed (8). But there is nothing in the problem that justifies singling out the initial old for special treatment. In short, take-go is a decision to substitute inefficient for efficient policy, making all current young and future generations worse off in the process. ${ }^{1}$

\footnotetext{
${ }^{1}$ Note, though, that once the $T^{*}$ policy is implemented, it may be possible to gradually move to first-best policy by substituting take-go policy for progressive tax policy, achieving a Pareto improvement in the process. We leave this question for future work.
} 


\section{Takeaways}

Model 1 has five explicit or implied takeaways. First, in dynamically efficient economies, where the marginal product of capital exceeds the growth rate, the only reason safe rates lie below growth rates is risk. ${ }^{2}$ Second, shocks that drive the safe rate below the growth rate, can arise due to inefficient risk sharing regardless of the micro or macro nature of the shocks. If that's the case, improving risk sharing, not running take-go policy, is the economic prescription. And it's a prescription that needs to be explored before it's too late, i.e., before take-go is implemented and young and future generations are, as a group, precluded from enjoying the full gains from immediately adopting first-best, risk-sharing policy. Third, the larger the risk, in this case, the larger the value of $\theta$, the lower will be $S$ and the greater will be the temptation to run deficits (take-go) that disenfranchises some or all young and future generations relative to the first best. Fourth, adopting and maintaining second-best policy, if not reversed, permanently lowers the economy's output starting just one period after take-go is initiated. Fifth, relative to running the risk-sharing policy, either immediately or down the road, engaging in take-go is a government-organized Ponzi scheme - making early participants better off and inducing future cohorts to participate in what is a hard-to-discern bad deal to recoup their "investment".

In sum, the carpenter's creed - Measure twice and cut once. - fully applies. In this case, it is crucial to first understand why safe rates are low and to consider risk mitigation policies, instead of simply taking from the young to give to the old.

\section{Take-Go Policy Uncertainty}

While model 1 assumes only idiosyncratic risk, models 2 and 3 assume only aggregate risk. Now aggregate capital returns are either $R H$ or $R L$. In addition, model 2 includes uncertainty over whether a take-go scheme - transferring $T$ from the young to the old - will be terminated. In particular, each period consumption can equal one of the following four equally likely values.

High returns, take-go retained:

$$
C_{t+1, A}=\alpha(1-T) S+(1-\alpha)(1-T) R H+T,
$$

Low return, take-go retained:

$$
C_{t+1, A}=\alpha(1-T) S_{t}+(1-\alpha)(1-T) R L+T,
$$

High returns, take-go terminated:

$$
C_{t+1, A}=\alpha(1-T) S_{t}+(1-\alpha)(1-T) R H
$$

Low returns, take-go terminated:

$$
C_{t+1, A}=\alpha(1-T) S_{t}+(1-\alpha)(1-T) R L
$$

\footnotetext{
${ }^{2}$ Idiosyncratic- as well as aggregate-return risk can explain low safe rates. Moreover, uninsured idiosyncraticrisk, including non-return-related idiosyncratic risk, can exacerbate macro-return risk. For example, idiosyncratic second-period, labor-income uncertainty, arising from health or other factors, can lower $S$ below 1 , when it would not otherwise fall below 1 due to macro-return risk by itself. In this case, improved intra-generational risk sharing, via progressive wage taxation, can, potentially, raise $S$ above 1, raising all generations' welfare and eliminating the argument for deficit finance.
} 
The solution, given in (21), for $S$, assuming isoelastic utility, now incorporates states in which take-go is randomly eliminated to the cost of the contemporaneous elderly. This places government-generated policy uncertainty in high relief. Other policies, such as a gradual reduction in the scale of take go starting at an uncertain time, would have different implications for the path of $S .^{3}$ As for this setup, we have

$$
S=R H \omega+R L(1-\omega)
$$

where

$$
\omega=\frac{(A+B) C D}{(A+B) C D+(C+D) A B}
$$

and

$$
\begin{aligned}
& A=((1-T)(S-R H)+T)^{\gamma}, B=((1-T)(S-R H))^{\gamma}, \\
& C=((1-T)(S-R L)+T)^{\gamma}, D=((1-T)(S-R L))^{\gamma} .
\end{aligned}
$$

As $T$ increases from zero, the policy first reduces and then raises risk. Consequently, $S$ rises and then falls. When utility is logarithmic, $S=R H L$ at the extremes, $T=0$ and $T=1$. For our standard parameters, $R H L=0.9$. $S$ peaks at 0.943 for $T=0.595$. Values of $T$ above 0.595 make take-go look cheaper with $S$ dropping to 0.9 . Hence, above 0.595 , increasing $T-$ expanding take-go - makes deficit finance appear cheaper as it becomes economically more damaging. For higher risk aversion, $S$ is lower, but the pattern with respect to increases in $T$ is similar. Take $\gamma=2 . S=0.720$ at the extremes and peaks at 0.747 for $T=0.408$.

\section{Takeaways}

Higher $T$ means higher dependency on take go and higher risk associated with its possible elimination. Hence, unlike model 1, a higher value of $T$ can entail a lower value of $S$. Thus, model 2 delivers the alarming possibility that increased deficit finance will lower the safe rate, "justifying" even greater deficit finance. As $T$ is raised toward 1, expected utility declines. The broader message here is that policy enacted can be policy reversed. An apt example here is the Russian hyperinflation of 1998, which greatly reduced the real value of state pensions provided to a large segment of Russian retirees.

\section{When Private Borrowing Rates Exceed Lending Rates}

Our third model also assumes macro-return risk with $R H$ or $R L$ equally likely. But now there is no potential for policy reversal. Instead, this model features two safe rates - a low lending rate and a high borrowing rate, the wedge between the two being driven by transaction costs. Each generation contains $A$ - and $B$-type workers in equal proportion. $A$ workers earn 1 when young and 0 when old. $B$ workers earn 0 when young and 1 when old. $A$ workers consume when old. $B$ workers consume when young. Let $\delta>1$ denote a transactions cost wedge between the borrowing rate, $S \delta$ and the lending rate, $S$. Both types have logarithmic utility. In equilibrium, the lending of the $A \mathrm{~s}, \alpha_{A}$, equals the borrowing of the $B \mathrm{~s}, 1 /(S \delta)$, who borrow in full against their future wages. The As maximize

\footnotetext{
${ }^{3}$ Eliminating or dramatically reducing take-go may reflect a decision to raise output.
} 


$$
E U_{A, t}=.5 \log \left[\alpha_{A} S+\left(1-\alpha_{A}\right) R H\right]+.5 \log \left[\alpha_{A} S+\left(1-\alpha_{A}\right) R L\right] .
$$

Optimal $\alpha_{A}$ satisfies

$$
\alpha_{A}=[R L(R H-S)+R H(R L-S)] /[2(S-R H)(S-R L)] .
$$

In equilibrium,

$$
[R L(R H-S)+R H(R L-S)] /[2(S-R H)(S-R L)]=1 /[S \delta] .
$$

Now suppose the government, observing that it can borrow at less than 1, adopts take-go policy at scale $T$. Based on (12), this policy raises the expected utility of the $A$ s and lowers that of the $B$ s. Hence, the observation that one group's safe rate is below the growth rate provides no basis, even with linear technology, for suggesting take-go policy is free, i.e., Pareto improving. Comparing "the" safe rate with the growth rate is fallacious since there are two safe rates - one above and one below the growth rate. What about running take-go by having the government take just from and give just to the $A$ s by setting $T \leq T^{*}$ ? This helps current and future $A \mathrm{~s}$, but it hurts the $B \mathrm{~s}$ by reducing the supply of loans from $\alpha$ to $\alpha\left(1-T^{*}\right)$, raising equilibrium $S$ and, thus, the borrowing rate, $S \delta$.

\section{Takeaways}

In actual economies, safe borrowing rates invariably exceed growth rates by a wide margin. The borrowing-lending wedge may reflect, as assumed here, transactions costs. Or it could arise from discrimination, the risk of borrower default, market segmentation, asymmetric information, etc. Whatever its source, the wedge can't simply be assumed away. Its presence suggests that improved financial intermediation, potentially assisted via government loan-verification, loancollection, loan-enforcement, or idiosyncratic risk-reduction policies, not take-go, is the channel for Pareto improvement.

\section{Conclusion}

Safe rates that average less than growth rates make deficit finance alluring. But low safe rates can reflect incomplete intragenerational risk sharing, government-generated uncertainty, credit market imperfections, and, as Brumm et al. (2021) show, some combination of incomplete intergenerational risk sharing, incomplete international risk sharing, and beggar-thy-neighbor policy. In all such cases, take-go policy, a.k.a, deficit finance, is not free. It redistributes across generations, across nations, or within generations. And if take-go does Pareto improve, it may reflect second-best policy that leaves young and future generations worse off relative to enacting first best policy - policy that addresses the root cause of low safe rates. Moreover, uncertainty about the resolution of government debt policies can, itself, lower the government's borrowing rate, making deficits look cheaper precisely when they are becoming economically more expensive. 


\section{References}

Blanchard, O. (2019). Public debt and low interest rates. American Economic Review, 109(4):1197-1229.

Blanchard, O., Leandro, A., and Zettelmeyer, J. (2020). Revisiting the EU fiscal rules in an era of low interest rates. In Rethinking the European Fiscal Framework Conference.

Blanchard, O. and Summers, L. H. (2019). Evolution Or Revolution?: Rethinking Macroeconomic Policy After the Great Recession. MIT Press.

Brumm, J., Feng, X., Kotlikoff, L., and Kubler, F. (2021). When interest rates go low, should public debt go high? Working Paper, National Bureau of Economic Research, forthcoming.

Summers, L. H. and Rachel, L. (2019). On falling neutral real rates, fiscal policy and the risk of secular stagnation. In Brookings Papers on Economic Activity BPEA Conference Drafts, volume 8 . 